\title{
Destruction of a translationally controlled mRNA in Xenopus oocytes delays progesterone-induced maturation
}

\author{
Rosamund C. Smith, Mark B. Dworkin, and Eva Dworkin-Rastl \\ Ernst-Boehringer-Institut, A-1121 Vienna, Austria
}

The maternal mRNA D7 is a moderately abundant transcript in Xenopus laevis whose expression is highest in, and perhaps restricted to, oogenesis and early embryogenesis. The nucleotide sequence of cloned D7 cDNA was determined and shown to have the capacity to code for a $31-\mathrm{kD}$ protein. This amino acid sequence was searched against a protein data base, and no homologous proteins were found. Antibodies directed against D7 recognize in Xenopus embryos a soluble, cytoplasmic protein with an apparent molecular weight on SDS gels of 36,000 . The $\mathrm{D} 7$ protein is absent from oocytes and first begins to accumulate during oocyte maturation. Its levels are highest during the first day of embryonic development and then decrease; $D 7$ protein was not detected in adult tissues. D7 mRNA was selectively destroyed by injection into oocytes of antisense oligodeoxynucleotides. Analysis of injected oocytes by Northern and Western blotting showed site-specific cleavage and subsequent degradation of the D7 mRNA and the failure of the D7 protein to accumulate during progesterone-induced maturation. The loss of $\mathrm{D} 7$ protein affects the maturation process itself, significantly delaying the time course of germinal vesicle breakdown. Thus, D7 is a newly described protein involved in oocyte maturation.

[Key Words: Xenopus laevis; maternal mRNA; translational control; antisense oligodeoxynucleotide; oocyte maturation]

Received May 30, 1988; revised version accepted July 25, 1988.

Recombinant DNA technology has permitted the isolation of genes that are active during well-defined periods of development. cDNA libraries prepared from Xenopus oocyte mRNA have been used for the isolation of maternal RNAs whose presence is restricted to oogenesis and early embryogenesis and that may code for proteins important for oocyte maturation, cleavage divisions, or early pattern formation (Dworkin et al. 1985). Some of these sequences are translationally silent in oocytes until (at least) oocyte maturation (Dworkin et al. 1985). The fact that the accumulation of the translation products of these mRNAs in oocytes is prevented indicates that they do not represent structural components of the oocyte and suggests that premature expression of these proteins might be detrimental to proper development.

The functional significance of particular genes is generally determined by the isolation of mutants that do not express that gene and examination of the resulting phenotype. It is difficult, however, to isolate maternal effect mutants in vertebrates and difficult in most species to construct specific mutants starting with cloned genes. An advantage of concentrating on sequences that are translationally repressed in oocytes is that they are amenable to a quasi-genetic approach of constructing phenocopies of deletion mutants. This involves the destruction of the particular mRNA in oo- cytes, followed by in vitro maturation and fertilization. Recent progress in fertilization of in vitro matured Xenopus oocytes may make such a strategy feasible (Holwill et al. 1987; J. Roberts and J. Gerhart, pers. comm.). Inhibition of translation in Xenopus oocytes of exogenous and endogenous mRNAs has been achieved by injecting antisense RNA into these cells (Harland and Weintraub 1985; Melton 1985; Wormington 1986). However, the presence of an RNA duplex unwinding activity in early Xenopus embryos (Bass and Weintraub 1987; Rebagliati and Melton 1987) limits the use of antisense RNA to studies in oocytes. An alternative approach employing antisense oligodeoxynucleotides has been developed in parallel, and specific translation inhibition in Xenopus oocytes was demonstrated initially for exogenous mRNAs (Kawasaki 1985; Cazenave et al. 1986). Recently, these studies were extended to include endogenous oocyte mRNAs, and the likely mechanism was shown to involve RNase $\mathrm{H}$-mediated cleavage of the oligodeoxynucleotide-mRNA hybrid (Dash et al. 1987; Jessus et al. 1988; Shuttleworth and Colman 1988).

In this paper we describe the cloned sequence D7, its nucleotide sequence, and the developmental expression pattern of the mRNA and its translation product in Xenopus laevis. As an initial approach to analyze the function of the D7 protein, oligodeoxynucleotide-mediated destruction of the D7 mRNA in Xenopus oocytes 
was carried out. Subsequent in vitro maturation of such oocytes revealed interference in the maturation process, manifested as a pronounced delay in the maturation time course.

\section{Results}

Developmentally restricted expression of $D 7 \mathrm{mRNA}$ and protein

A cDNA clone called D7.0 (originally D7; Dworkin and Dworkin-Rastl 1985) was derived from a moderately abundant $X$. laevis maternal mRNA (D7 mRNA) that is present throughout oogenesis but decreases in titer to very low levels within 2 days of development (Fig. 1). The amount of this RNA in the adult tissues examined is at or below the level of detection (Fig. 1). Antibodies to the D7 protein, obtained from rabbits immunized with a fusion protein consisting of part of the putative D7 polypeptide fused to Escherichia coli $\beta$-galactosidase (Materials and methods), recognized on Western blots a single $36-\mathrm{kD}$ protein that was expressed in a developmentally restricted pattern (Fig. 2). D7 protein was absent (at this level of detection) from stage VI oocytes (as well as from stage I-IV oocytes; data not shown), consistent with the nonpolysomal fractionation of D7 mRNA in these cells (Dworkin et al. 1985). Lysates from unfertilized eggs, however, reacted with the purified antibodies, demonstrating that translation of D7 mRNA and accumulation of $\mathrm{D} 7$ protein begin during oocyte maturation. The level of D7 protein was highest in embryos during the first day of development and then decreased, in accordance with the developmental profile of D7

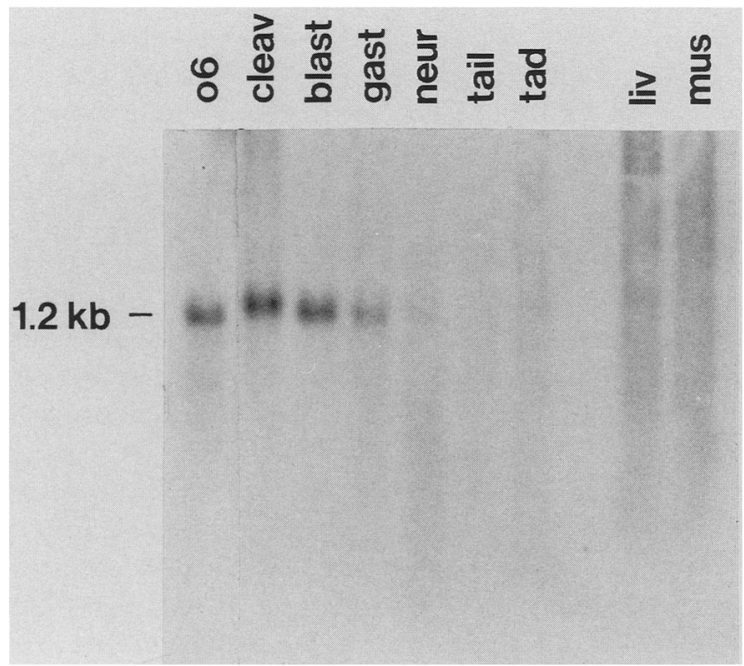

Figure 1. Northern blot analysis of Xenopus RNA probed with nick-translated plasmid D7.0. The first seven lanes contain 10 $\mu \mathrm{g}$ total RNA per lane from (left to right) stage VI oocytes, stages $61 / 2-7$ cleavage embryos, stage 9 blastulae, stages 10 1/2-12 gastrulae, stages 17-20 neurulae, stages $24-26$ early tailbud embryos, and stages 37-41 tadpoles. Liver (liv) and muscle (mus) lanes contain 0.8 and $0.4 \mu \mathrm{g}$ poly(A) + RNA, respectively.

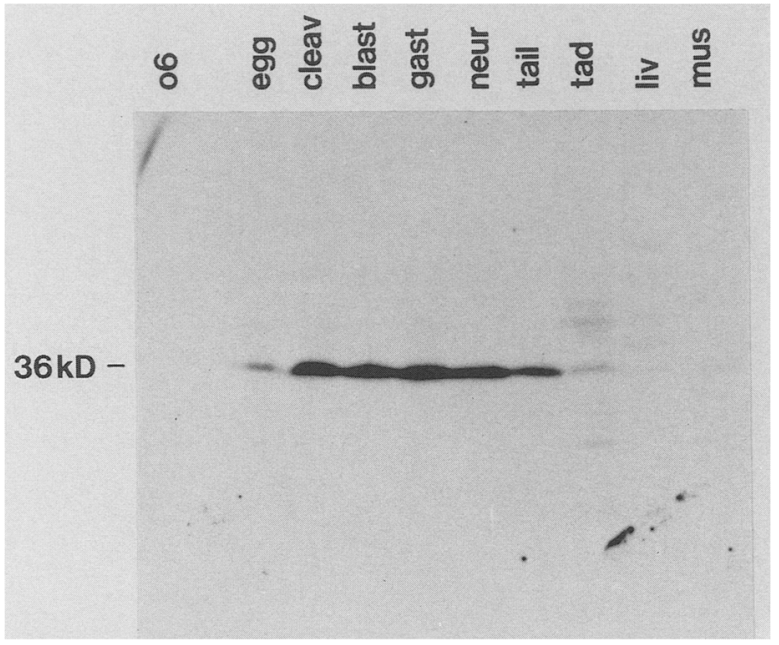

Figure 2. Western blot analysis of the developmental expression of D7 protein. The first eight lanes contain four embryo equivalents of protein per lane from (left to right) stage VI oocytes, unfertilized eggs, stages $2-7$ cleavage embryos, stages 9-10 late blastulae, stages $11-12$ gastrulae, stages $16-23$ neurulae, stages 28-34 tailbud embryos, and stages 40-41 tadpoles. Liver (liv) and muscle (mus) lanes contain $\sim 100 \mu \mathrm{g}$ protein.

mRNA. No D7 protein was detected in adult muscle or liver.

In situ immunofluorescence of paraffin sections of cleavage embryos with anti-D7 antibodies showed cytoplasmic labeling with no obvious localization within the embryo; nuclei were not stained (data not shown). Subcellular fractionation studies indicated that D7 is a soluble, cytoplasmic protein (data not shown).

\section{Sequence of two D7 CDNA clones and the putative D7 protein}

The size of D7 mRNA on Northern blots is $\sim 1200 \mathrm{nu}-$ cleotides. Because the clone initially isolated contained a cDNA insert of $898 \mathrm{bp}$ [excluding poly(A) and cloning tails], it was not a full-length clone. Therefore, another cDNA library constructed from egg poly(A) ${ }^{+}$RNA was screened for additional D7 cDNA sequences. A new clone, D7.1, was thus obtained, and it contained 153 additional nucleotides at the $5^{\prime}$ end but lacked 131 nucleotides at the $3^{\prime}$ end (Fig. 3A), compared with clone D7.0. The cDNA inserts of both clones were completely sequenced (Fig. 3). The two sequences were identical in the 767 nucleotides of overlapping region, except for two single mismatches (positions 611 and 785; Fig. 3A). Whereas the mismatch at position 785 is a silent change, the mismatch at nucleotide position 611 causes the introduction of a stop codon in clone D7.0 into what is a continuous open reading frame (ORF) in clone D7.1. The shorter ORF of clone D7.0 has a coding capacity for a $22-\mathrm{kD}$ protein, whereas the longer ORF of clone D7.1 has a coding capacity for a $31-\mathrm{kD}$ protein, which is close to the size of the protein recognized by the anti-D7 antibodies (Fig. 2). To test whether both types of sequences were represented in oocyte and egg mRNA, sequence- 
A

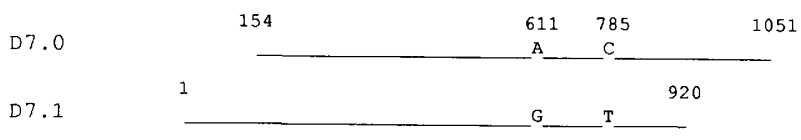

B

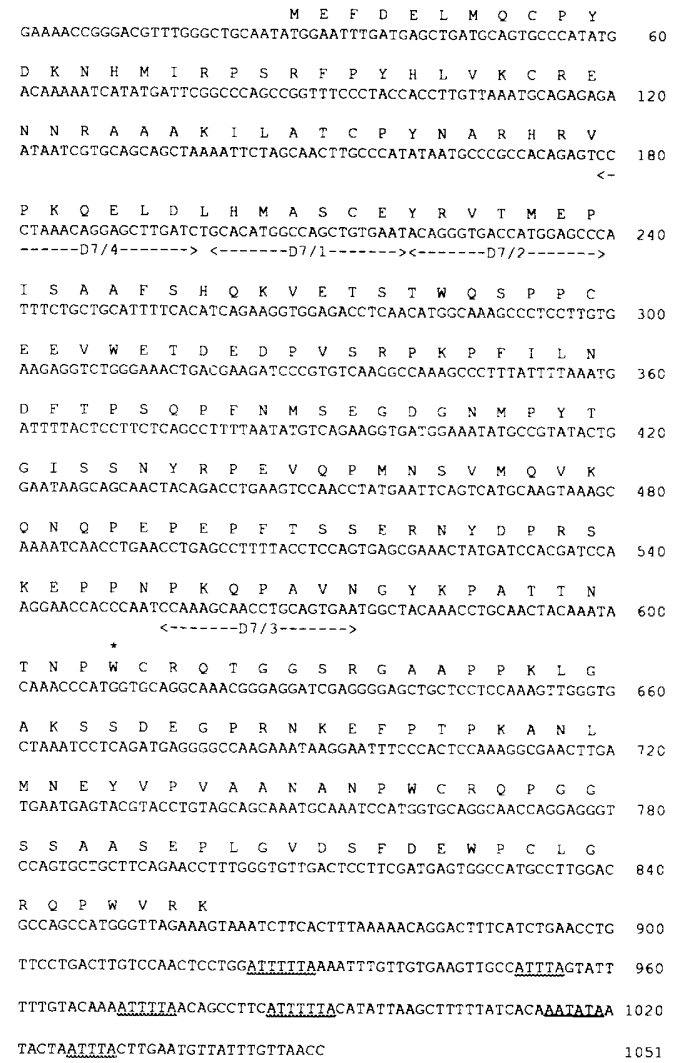

Figure 3. Nucleotide sequence of D7 cDNA and predicted amino acid sequence of D7 protein. (A) Relationship between clones D7.0 and D7.1. The nucleotide positions at the beginning and end of each clone are indicated above the horizontal lines representing the clones in the $5^{\prime}$ to $3^{\prime}$ direction. The two nucleotide differences between the two clones are shown with their respective nucleotide positions. $(B)$ The nucleotide and amino acid sequences shown are composites from D7.0 and D7.1, with the D7.1 sequence given at the two positions of mismatch. The position of the stop codon at the end of the ORF in clone D7.0 is indicated by an asterisk $\left({ }^{*}\right)$ (see text). The positions complementary to oligonucleotides D7/1-D7/4 are indicated by dashed arrows, $\mathrm{A}(\mathrm{T})_{n} \mathrm{~A}$ regions by wavy underlines, and the presumptive polyadenylation signal AATATA by a solid underline.

specific oligonucleotide probes were made to the nucleotide region in question for each of the two clones (Table 1).X. laevis oocyte and egg poly (A) ${ }^{+}$RNA were hybridized under differential hybridization conditions to each of the two oligonucleotide probes (Fig. 4; see also Materials and methods). Hybridization to the RNA was much stronger with the D7.1-specific oligonucleotide. Thus, we conclude that D7 mRNA predominantly for exclusively) consists of molecules of the D7.1 type, lacking the stop codon at nucleotide positions 609-611.

The composite D7 mRNA sequence (Fig. 3B), consisting of the complete D7.1 sequence and the $3^{\prime}$ extension derived from D7.0, is 1051 nucleotides long. Primer extension analysis indicated that the D7 transcript extends another 27 nucleotides beyond the $5^{\prime}$ end of the cloned cDNA (data not shown). The first ATG codon in the cloned sequence is at nucleotides $27-29$ and lies in a good sequence context for translation initiation (Kozak 1987). The ORF has a coding capacity for 278 amino acids. Because no in-frame stop codon is present $5^{\prime}$ to this ATG codon in the cloned sequence, a short extension of the ORF upstream cannot be excluded. The $3^{\prime}-$ noncoding region is 191 nucleotides long, is very AT rich $\mid 73 \%)$, and contains several $A(T)_{n} A$ motifs $(n=3-5)$ (Fig. 3B). The presence of AU-rich sequences, including $\mathrm{A}(\mathrm{U})_{n} \mathrm{~A}$ motifs, in the $3^{\prime}$-noncoding region of eukaryotic mRNAs has been correlated with transcript instability (Shaw and Kamen 1986). A potential polyadenylation signal (AATATA) is located 33 nucleotides from the $3^{\prime}$ end. This suggests that the complete 3 '-noncoding sequence is contained in the cDNA clone (D7.0), although this cannot be known with certainty because the cDNA library from which clone D7.0 was isolated had been constructed by AT tailing (Dworkin and Dworkin-Rastl 1985).

The putative polypeptide coded for by the ORF has a calculated pI of 7.00. It is mostly hydrophilic and lacks any long hydrophobic region, consistent with it being a soluble protein (data not shown). Its calculated molecular weight of 31,364 is lower than the apparent molecular weight on SDS gels $(36,000)$ observed for the immunoreactive Xenopus protein. Because the D7 protein synthesized in vitro by translation of egg poly $(A)^{+}$RNA and isolated by immunoprecipitation also shows an apparent molecular weight on SDS gels of 36,000 (data not shown|, the difference between the apparent and calculated molecular weights is most likely due to aberrant migration on SDS gels. The putative D7 amino acid sequence showed no significant homology to any sequence in the protein sequence data base of the Protein Identification Resource. Although we have not yet directly tested whether D7 is a phosphoprotein, it does not contain an obvious recognition site for protein kinase A (Edelman et al. 1987) and does not itself appear to be a protein kinase (Doolittle 1986; Brenner 1987; Bairoch and Claverie 1988). The D7 protein does contain a region rich in proline $(P)$, glutamic acid $(E)$, serine $(S)$, and threonine (T) ('PEST' region), flanked with the positively charged residues lysine and arginine lamino acids $151-165$, Fig. 3B). Such regions are found preferentially in proteins with short intracellular half-lives (Rogers et al. 1986) and could indicate a high turnover rate for D7.

\section{Oligonucleotide-mediated degradation of $D 7 \mathrm{mRNA}$}

To analyze the possible function of D7 protein, we attempted to construct phenocopies of null mutants for D7 by eliminating D7 mRNA from the oocyte. Toward 
Table 1. Synthetic oligodeoxynucleotides

\begin{tabular}{lll}
\hline Designation & Sequence $\left(5^{\prime}\right.$ to $\left.3^{\prime}\right)$ & Complementarity \\
\hline EBI1016 & TTGCCTGCATCATGGGTTT & nucleotides 602-620; specific for D7.0 \\
EBI1017 & TTGCCTGCACCATGGGTTT & nucleotides 602-620; specific for D7.1 \\
D7/1 & ATTCACAGCTGGCCATGTGC & nucleotides 200-219 \\
D7/2 & GGGCTCCATGGTCACCCTGT & nucleotides 220-239 \\
D7/3 & TTCACTGCAGGTTGCTTTGG & nucleotides 555-574 \\
D7/4 & GATCAAGCTCCTGTTTAGGG & nucleotides $179-198$ \\
EBI896 & GGTTTGCT AGTAGTGCTAAG & \\
EBI898 & CAGGAGATGGTAAAAGG & \\
\hline
\end{tabular}

Oligonucleotides EBI1016 and EBI1017 were used as hybridization probes specific for sequences D7.0 and D7.1, respectively; oligonucleotides D7/1-D7/4 were used for injection into oocytes to mediate D7 mRNA degradation; oligonucleotides EBI896 and EBI898 were used as controls in injection experiments (they have no known complementarity to $X$. laevis DNA). The nucleotide positions indicated refer to the $\mathrm{D} 7$ sequence given in Fig. 3B.

this end, four different 20-mer oligonucleotides (D7/1D7/4), complementary to D7 mRNA, were synthesized (Table 1; Fig. 3B) and injected into stage VI oocytes. Hybridization of the oligonucleotides to D7 mRNA would likely be followed by cleavage of the RNA-DNA hybrid by an RNase $\mathrm{H}$ activity present in oocytes (Cazenave et al. 1987b; Dash et al. 1987; Shuttleworth and Colman

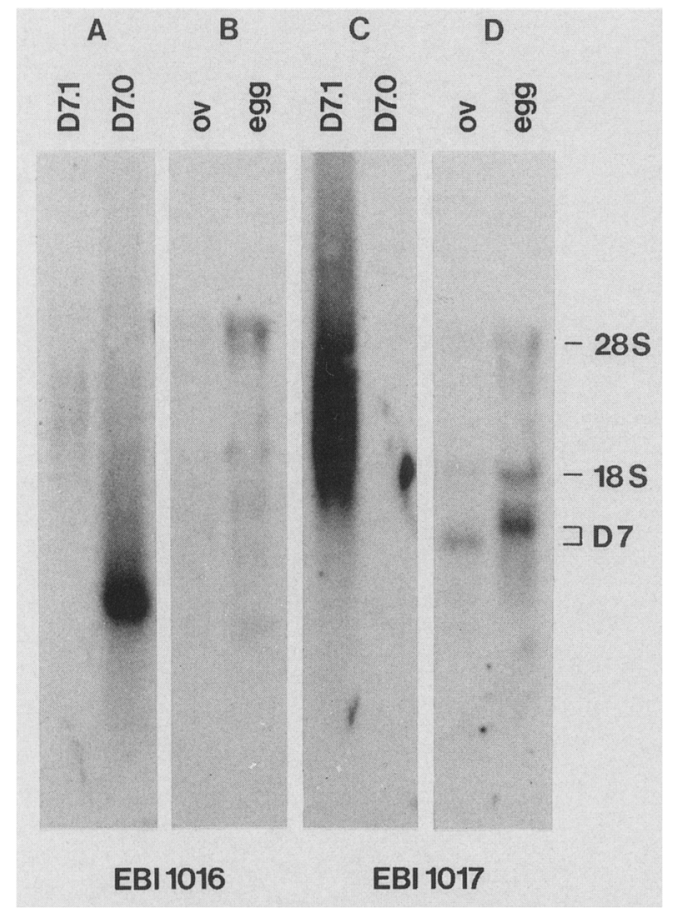

Figure 4. Differential hybridization of oligodeoxynucleotides to D7 SP6 transcripts and Xenopus RNA. SP6 transcripts $15 \mathrm{ng}$ per lane) of D7.1 type and D7.0 type $(A, C)$, or poly $(\mathrm{A})^{+}{ }^{+} \mathrm{RNA}(3$ $\mu \mathrm{g}$ per lane) from total ovary (ov) and unfertilized eggs (egg) $(B, D)$ were hybridized under differential hybridization conditions (Materials and methods) with the D7.0-specific oligonucleotide EBI1016 $(A, B)$ or the D7.1-specific oligonucleotide EBI1017 (C,D). D7 mRNA (D7) is slightly larger in egg RNA than in ovary RNA, probably due to increased length of the poly(A) tail. rRNAs (28S and $18 \mathrm{~S}$ ) show nonspecific reaction with the probes.
1988). The effect of the injection of D7 mRNA was assayed by extracting total RNA from the injected oocytes and probing for the integrity of D7 mRNA by Northern blot analysis. Injection of anti-D7 oligonucleotides resulted in a discrete shortening of D7 mRNA within $1 \mathrm{hr}$, the size shift in each case being consistent with an RNase H-mediated cleavage of the RNA-oligonucleotide hybrid (Fig. 5A; with D7/1, D7/2, and D7/4, only the larger 3'-cleavage products are seen on the gels). All oligonucleotides resulted in a reduction in the amount of full-length D7 mRNA. Oligonucleotides D7/2 and D7/3 were more efficient in mediating degradation of $\mathrm{D} 7$ mRNA than D7/1 and D7/4, reducing the amount of D7 mRNA to undetectable levels. The RNA cleavage product mediated by oligonucleotide $\mathrm{D} 7 / 4$ was the least stable compared with intermediates generated with D7/1, D7/2, and D7/3 (Fig. 5A). Upon continued incubation of the injected oocytes, these shortened transcripts were degraded (Fig. 5B). There was no evidence of new transcription of D7 mRNA during the incubation times. The same result was obtained when incubation was carried out in the presence of progesterone to induce maturation (see below; data not shown). However, we did observe some variation in the time courses of D7 mRNA cleavage among different batches of oocytes. To control for RNA yield and quality, the RNA blots were either cohybridized with, or stripped of the radioactive D7 probe and rehybridized with, a probe for a different maternal mRNA, A10 (Fig. 5; Dworkin et al. 1985). The observed persistence of A10 mRNA excludes a nonspecific effect of the anti-D7 oligonucleotide on mRNA in general. Also, injection of a control oligonucleotide (EBI898, Table 1), not complementary to D7 mRNA, did not affect D7 mRNA levels (Fig. 5A). Thus, the degradation of D7 mRNA is a sequence-specific event. In some batches of oocytes, two RNA bands hybridized with the D7 probe (Fig. 5B,C). Both transcripts were degraded upon injection of the antisense oligonucleotide.

The oligonucleotide-mediated degradation of D7 mRNA required considerable amounts of oligomer to be effective. In the experiments shown in Figure 5, A and B, $60 \mathrm{ng}$ of oligonucleotide per oocyte was injected. When 20 ng per oocyte (oligonucleotide D7/1) was injected, a size shift occurred in only a fraction of the D7 mRNA 

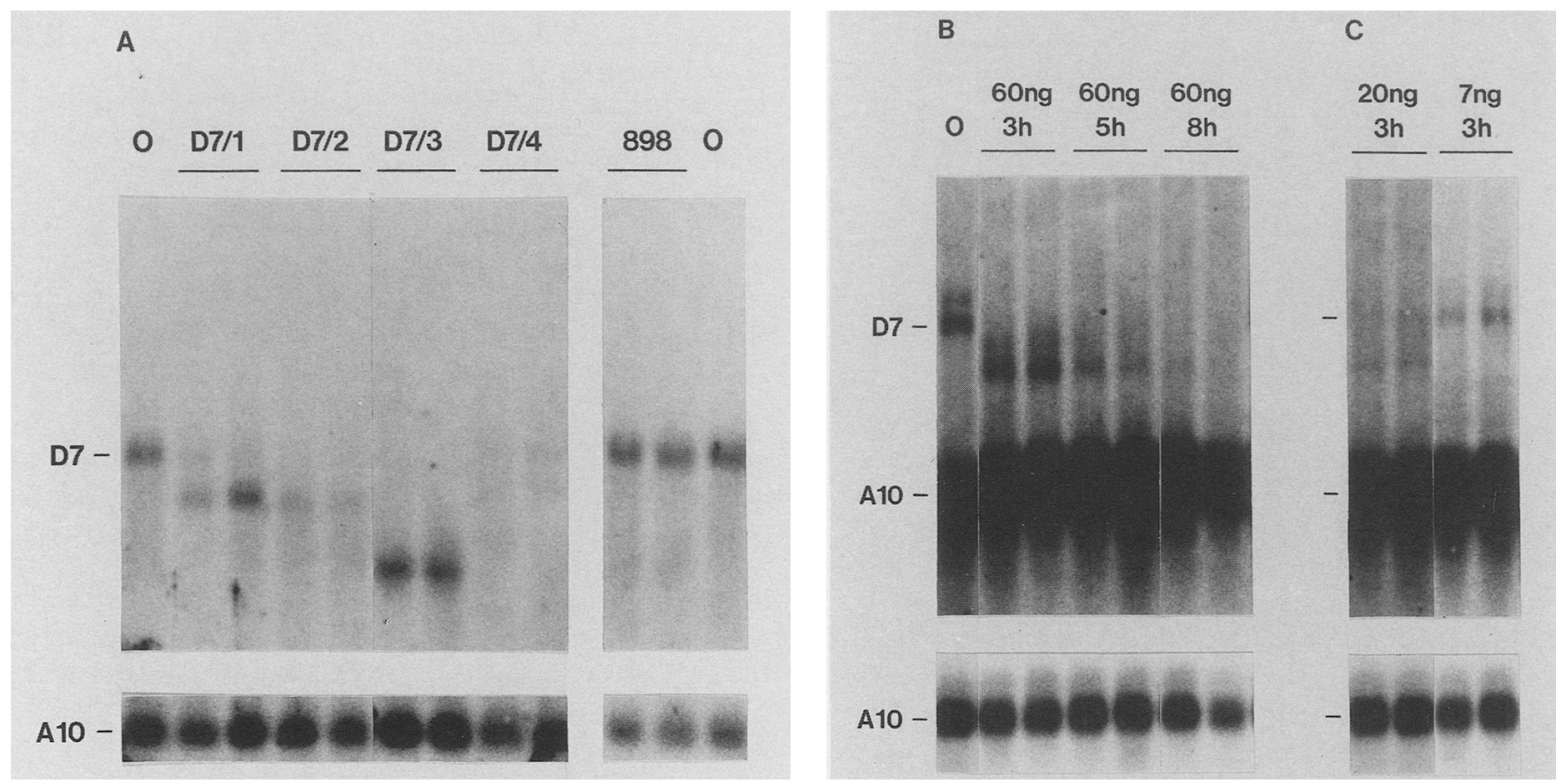

Figure 5. Northern blots of total RNA from oocytes injected with antisense oligonucleotides. $(A)$ Comparison of different oligonucleotides. (D7/1-D7/4) Oocytes injected with $60 \mathrm{ng}$ antisense oligonucleotides against D7 mRNA; (898) oocytes injected with $60 \mathrm{ng}$ control oligonucleotide EBI898; (O) uninjected stage VI oocytes. RNA was extracted $1 \mathrm{hr}(\mathrm{D} 7 / 1-\mathrm{D} 7 / 4)$ or $3 \mathrm{hr}(898)$ after injection. Blots were first hybridized with nick-translated plasmid D7.0, stripped of the probe, and rehybridized with nick-translated plasmid Al0 (Dworkin et al. 1985) (for the three right-most lanes, a shorter exposure of A10 is shown than for the other lanes). (B) Time course of degradation of D7 mRNA after injection of antisense oligonucleotide. RNA was extracted 3, 5, or $8 \mathrm{hr}$ after injection of $60 \mathrm{ng}$ oligonucleotide D7/1 per oocyte. $(O)$ uninjected stage VI oocytes. $(C)$ Dependence of D7 mRNA degradation on antisense oligonucleotide concentration. RNA was extracted $3 \mathrm{hr}$ after injection of $20 \mathrm{ng}$ or $7 \mathrm{ng}$ oligonucleotide D7/1 per oocyte. The blots shown in $B$ and $C$ were cohybridized with nick-translated plasmids D7.0 and A10. A shorter exposure of the region of A10 hybridization is shown at bottom. (D7) Full-length D7 mRNA; (A10) A10 mRNA. In the oocytes used in experiments $B$ and $C$, the D7 probe recognized a slightly larger RNA species in addition to the main D7 mRNA band; both RNAs were cleaved after oligonucleotide injection.

molecules, and when $7 \mathrm{ng}$ of oligonucleotide per oocyte was injected, no size shift was observed (Fig. 5C). The requirement for such high levels of oligonucleotide for successful RNA elimination could be due to the instability of oligonucleotides in oocytes. To test this, ${ }^{32} \mathrm{P}$ end-labeled oligonucleotide (D7/1, $60 \mathrm{ng}$ per oocyte) was injected into oocytes, the oocytes were incubated up to $20 \mathrm{hr}$, and oocyte lysates were prepared and separated on a 20\% DNA sequencing gel (Fig. 6). Much of the ${ }^{32} \mathrm{P}$ label was rapidly lost, probably due, in part, to phosphatase activity. However, intermediate-size oligonucleotides were also detected, and by $3 \mathrm{hr}$, the amount of intermediate-sized oligonucleotides exceeded the amount of remaining 20-mer. After $6 \mathrm{hr}$ of incubation, only very short oligomers remained, as well as a small amount of 20-mer which did persist. Thus, during the course of incubation, the oligonucleotide was largely destroyed, possibly to deoxynucleotides. The gel also shows that initially some lengthening of the $20-\mathrm{mer}$ (to a 21 -mer) occurred in the oocytes. Instability of oligonucleotides in Xenopus oocytes has also been reported by Cazenave et al. (1987a).

In untreated oocytes, translation of D7 mRNA is induced during oocyte maturation (Fig. 2). Thus, in oocytes injected with anti-D7 oligonucleotides, D7 protein should not accumulate following induction of matura- tion. To test this, oocytes were injected with either the anti-D7 oligonucleotides or with a control oligonucleotide (EBI898, Table 1), incubated for $3 \mathrm{hr}$ in progesterone-free medium, and then treated with progesterone. Progesterone induced maturation of the injected oocytes, albeit with a delay in the case of oocytes injected with the D7-specific oligonucleotides (see below). Protein of matured oocytes was assayed by Western blotting with anti-D7 antibodies (Fig. 7). These blots were also coreacted with antiserum against Xenopus enolase, a protein whose level is unchanged during oocyte maturation (Segil et al. 1988), to demonstrate equal recovery of protein in the different samples. The results show that the level of D7 protein in matured oocytes was reduced with all experimental oligonucleotides; the D7 protein was reduced to background levels with oligonucleotides D7/1, D7/2, and D7/3. Injection of the control oligonucleotide did not affect D7 protein levels. Due to an abundant Coomassie blue-stainable protein at the position of D7 that gives a slight, nonspecific reaction to immunoglobulins, we cannot exclude the presence of low levels of D7 protein. By scanning autoradiographs of Western blots, we have determined that the background signal in stage VI oocytes at the D7 position is $20 \%$ the level of the D7 protein signal obtained from untreated in vitro-matured eggs. 


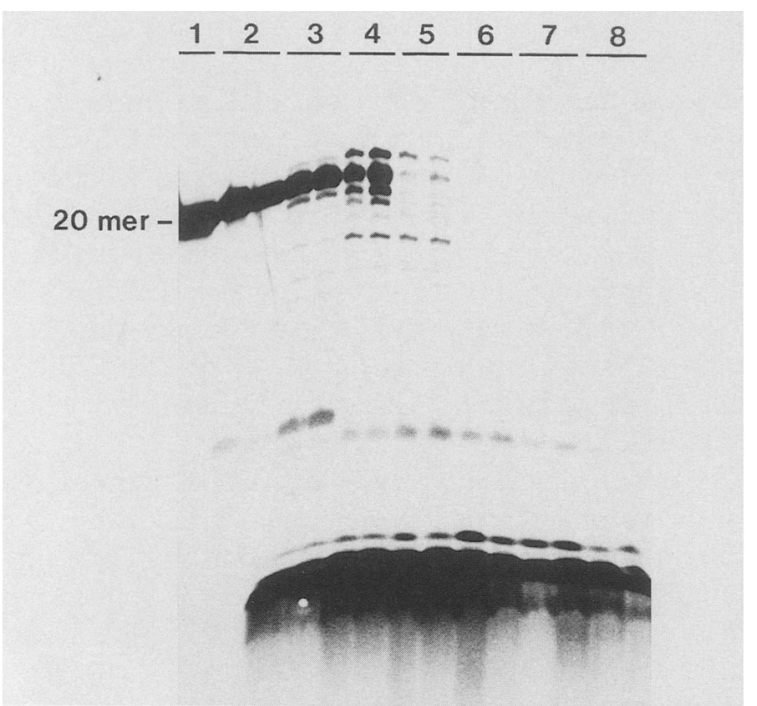

Figure 6. Time course of degradation of oligonucleotide injected into stage VI oocytes. End-labeled D7/1 oligonucleotide was prepared and injected into stage VI oocytes as described in Materials and methods. (Lane 1) Uninjected oligonucleotide; (lanes 2-8) injected oocytes incubated for $0 \mathrm{~min}, 22 \mathrm{~min}, 1 \mathrm{hr}, 3$ $\mathrm{hr}, 6 \mathrm{hr}, 9 \mathrm{hr}$, and $20 \mathrm{hr}$, respectively. Each lane is from a single oocyte; the two lanes shown for each time point (lanes 2-8) are from different injected oocytes.

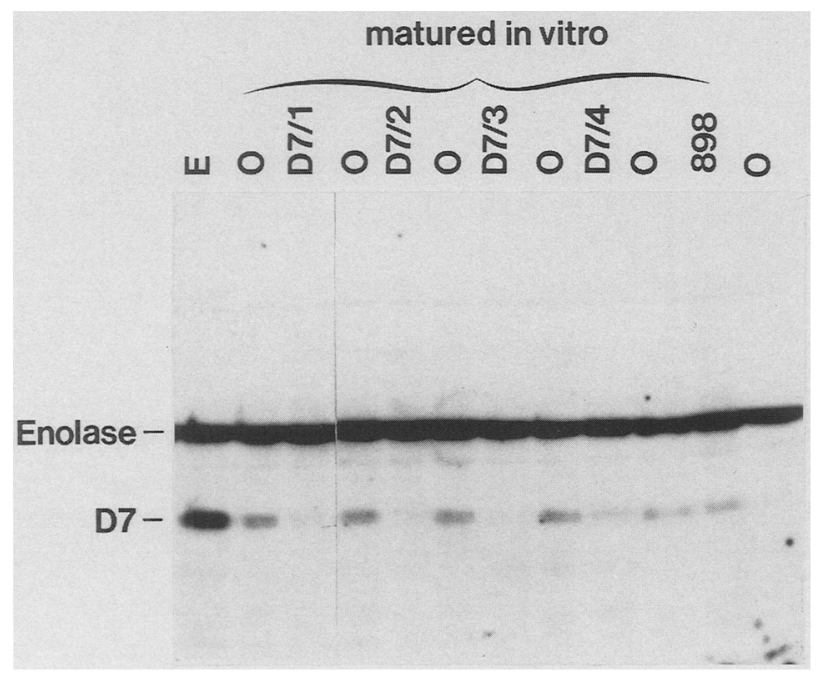

Figure 7. Western blot analysis of oocytes injected with antisense oligonucleotides and subsequently matured in vitro. Stage VI oocytes were injected with $60 \mathrm{ng}$ of antisense oligonucleotides against D7 mRNA (D7/1-D $7 / 4)$ or $60 \mathrm{ng}$ of the control oligonucleotide EBI898 (898), incubated for $3 \mathrm{hr}$, and then induced to mature by the addition of progesterone. Maturation time courses for this experiment are shown in Fig. 8. Mature oocytes were taken after incubation in progesterone for $10 \mathrm{hr}$ (D7/1), $8 \mathrm{hr}$ and $50 \mathrm{~min}(\mathrm{D} 7 / 2), 7 \mathrm{hr}$ and $30 \mathrm{~min}(\mathrm{D} 7 / 3), 6 \mathrm{hr}$ and $20 \mathrm{~min}(\mathrm{D} 7 / 4)$, and $5 \mathrm{hr}(898)$, and D7 protein analyzed in Western blots with anti-D7 antibodies. To control for recovery of protein, blots were coreacted with anti-enolase antiserum. For each time point, uninjected control oocytes were analyzed in parallel $(O$, to the left of each experimental lane; note the time-dependent increase in D7 protein in these control oocytes). (O, right-most lane) stage VI oocytes; $(E)$ unfertilized eggs.

\section{Delayed maturation of oocytes with reduced D7 protein levels}

Groups of stage VI oocytes were injected with $60 \mathrm{ng}$ per oocyte of oligonucleotides D7/1-D7/4 or with the control oligonucleotides EBI896 or EBI898 (Table 1). After a minimum of $3 \mathrm{hr}$ of incubation, the oocytes were transferred to medium containing progesterone. Maturation was scored visually under a dissecting microscope for formation of the white maturation spot. The results of six experiments (with oocytes from six different frogs) are shown in Table 2. In all experiments shown, uninjected oocytes as well as oocytes injected with the control oligonucleotides underwent $100 \%$ germinal vesicle breakdown (GVBD). Oocytes that had been injected with antisense oligonucleotides against D7 mRNA exhibited delays in the maturation time course. The extent of the delay depended on the oligonucleotide used (Fig. 8; Table 2), the most effective oligonucleotide being D $7 / 2$, followed by oligonucleotides D7/1 and D7/4. These oligonucleotides not only delayed GVBD but also caused a flattening of the slope in the curve of the maturation time course (Fig. 8). Although the delay of progesterone-

Table 2. Delay of progesterone-induced maturation after injection of anti-D7 mRNA oligonucleotides

\begin{tabular}{cllr}
\hline \multirow{2}{*}{ Experiment } & Oligonucleotide & Time & $\begin{array}{r}\text { Percent } \\
\text { mature }\end{array}$ \\
\hline 1 & none & $3 \mathrm{hr}, 45 \mathrm{~min}$ & 100 \\
& EBI898 & $3 \mathrm{hr}, 45 \mathrm{~min}$ & 100 \\
& D7/1 & $3 \mathrm{hr}, 45 \mathrm{~min}$ & 50 \\
D7/2 & $3 \mathrm{hr}, 45 \mathrm{~min}$ & 5 \\
& D7/3 & $3 \mathrm{hr}, 45 \mathrm{~min}$ & 83 \\
& D7/4 & $3 \mathrm{hr}, 45 \mathrm{~min}$ & 43 \\
2 & none & $5 \mathrm{hr}$ & 100 \\
& EBI898 & $5 \mathrm{hr}, 25 \mathrm{~min}$ & 100 \\
3 & D7/1 & $5 \mathrm{hr}, 25 \mathrm{~min}$ & 25 \\
& none & $10 \mathrm{hr}, 30 \mathrm{~min}$ & 100 \\
& EBI896 & $10 \mathrm{hr}, 30 \mathrm{~min}$ & 100 \\
4 & D7/2 & $10 \mathrm{hr}, 30 \mathrm{~min}$ & 6 \\
& none & $6 \mathrm{hr}, 30 \mathrm{~min}$ & 100 \\
& EBI896 & $5 \mathrm{hr}$ & 100 \\
& D7/2 & $6 \mathrm{hr}, 30 \mathrm{~min}$ & 9 \\
5 & D7/2 & $10 \mathrm{hr}, 15 \mathrm{~min}$ & 9 \\
& none & $9 \mathrm{hr}, 30 \mathrm{~min}$ & 100 \\
& EBI896 & $9 \mathrm{hr}, 30 \mathrm{~min}$ & 100 \\
6 & D7/2 & $9 \mathrm{hr}, 30 \mathrm{~min}$ & 8 \\
& none & $8 \mathrm{hr}, 30 \mathrm{~min}$ & 100 \\
& EBI896 & $8 \mathrm{hr}, 30 \mathrm{~min}$ & 100 \\
& D7/1 & $8 \mathrm{hr}, 30 \mathrm{~min}$ & 10 \\
& D7/2 & $8 \mathrm{hr}, 30 \mathrm{~min}$ & 4 \\
& D7/2 & $36 \mathrm{hr}$ & 4 \\
\hline & & & \\
& & &
\end{tabular}

Experiments 1 and 3 are identical to the experiments shown in Figs. 8 and 9, respectively. In experiments $1-5,60 \mathrm{ng}$ of oligonucleotide per oocyte was injected, and in experiment $6,130 \mathrm{ng}$ of oligonucleotide per oocyte was injected. GVBD was scored by visual inspection of maturation spots in experiments 1 and 2 , by analysis of paraffin sections in experiments $3-5$, and by dissection of trichloroacetic acid-fixed oocytes in experiment 6 . The earliest time when control oocytes showed $100 \%$ maturation is given. 
induced maturation with $\mathrm{D} 7 / 1$ - and $\mathrm{D} 7 / 2$-injected oocytes was very reproducible, the exact extent of the delay varied among different batches of oocytes. In some experiments, such as experiment 4 (Table 2) in which experimental oocytes (D $7 / 2)$ showed $<10 \%$ maturation after $10 \mathrm{hr}$ in progesterone (control oligonucleotide-injected oocytes showed $100 \%$ GVBD by $5 \mathrm{hr}$ ), maturation may have been essentially inhibited rather than only delayed. Using higher amounts of oligonucleotide D7/2 (130 ng per oocyte), it was possible to achieve complete inhibition of maturation (experiment 6, Table 2). In this experiment, all but one of the oocytes injected with the oligonucleotide failed to mature within the time of the experiment ( $36 \mathrm{hr}$ in progesterone), whereas uninjected oocytes or oocytes injected with control oligonucleotide (130 ng per oocyte) reached $100 \%$ GVBD after $8.5 \mathrm{hr}$ in progesterone. It is likely, then, that D7 mRNA was completely eliminated in this experiment (see Discussion).

Oligonucleotide D7/3 affected the time course of oocyte maturation only slightly (Fig. 8; Table 2), even though this oligonucleotide was very effective in causing cleavage of $\mathrm{D} 7 \mathrm{mRNA}$ (Fig. 5A) and reducing D7 protein levels in the matured oocytes (Fig. 7). Because oligonucleotide $\mathrm{D} 7 / 3$ hybridizes to a region in D7 mRNA much farther 3 ' than the other oligonucleotides tested (Fig. 3B), it may be that the cleavage product of the D7 mRNA can still code for a functional (but truncated) polypeptide. Such a truncated polypeptide was not detected, however, in Western blot experiments (Fig. 7).

In addition to undergoing delayed maturation, oocytes injected with oligonucleotides D7/1, D7/2, or D7/4 /'experimental oocytes') displayed a matured phenotype distinct from that of uninjected oocytes or oocytes injected with oligonucleotides EBI896 or EBI898 ('control oocytes'), or oocytes injected with the ineffective (with respect to delaying maturation) oligonucleotide D $7 / 3$. In particular, whereas control oocytes usually developed obvious white maturation spots surrounded by a ring of darker pigment, the appearance of the maturation spot in experimental oocytes was varied, depending on the particular batch of oocytes. In general, white spot formation was less distinct in experimental oocytes than in control oocytes, and frequently the animal hemisphere developed a mottled or 'swirly' appearance. Because of these pigment effects, the scoring of maturation spots under the dissecting microscope was often difficult in experimental oocytes; therefore, in some experiments the percentage of GVBD in a particular population of oocytes was scored histologically, after embedding the oocytes in paraffin and sectioning, or after fixation of oocytes in trichloroacetic acid and subsequent dissection (Table 2). The histological determination of GVBD almost always confirmed the prior evaluation of oocytes made under the dissecting microscope.

The experiment shown in Figure 5A had demonstrated that different oligonucleotides were differentially effective in mediating D7 mRNA degradation. These oligonucleotides caused delays in progesterone-induced maturation to different extents (Fig. 8; Table 2), consistent with their respective efficiencies for mRNA degradation (except for D7/3, above). This suggested that the extent of maturation delay was a function of residual D7 mRNA. We addressed this further by determining the relationship between the amount of a given oligonucleotide injected and the resultant delay in the maturation time course. As shown in Figure 5C, the efficiency of mRNA degradation depended very sensitively on the amount of oligonucleotide injected. Oligonucleotide D7/2 was injected into oocytes at three different concentrations (up to $60 \mathrm{ng}$ per oocyte in this experiment), the oocytes were incubated overnight $(>9 \mathrm{hr})$ in medium without progesterone, transferred to progesterone-containing medium, and the maturation time courses were followed by visual inspection under the dissecting microscope (Fig. 9). When control oocytes had reached $100 \%$ GVBD, all oocytes were fixed and processed for histological determination of GVBD. At this time, only $6 \%$ (1 of 18 ) of the oocytes that had been injected with $60 \mathrm{ng}$ of oligonucleotide $\mathrm{D} 7 / 2$ had matured, whereas in the same time period, $50 \%$ (8 of 16) of the oocytes injected with $30 \mathrm{ng}$, and $100 \%$ (14) of the oocytes injected with $15 \mathrm{ng}$ had matured. These results demonstrate a dependence of the delay in the maturation time course on the amount of oligonucleotide injected, which, in
Figure 8. Delay of in vitro maturation after injection into oocytes of antisense oligonucleotides against D7 mRNA. Stage VI oocytes were injected with $60 \mathrm{ng}$ of antisense oligonucleotides against D7 mRNA (D7/1-D7/4) or $60 \mathrm{ng}$ of the control oligonucleotide EBI898 (control), incubated for $3 \mathrm{hr}$, and induced to mature by the addition of progesterone. The number of oocytes injected per oligonucleotide was $\geqslant 21$. The time courses of maturation were determined by scoring the formation of maturation spots under the dissecting microscope. Noninjected and control oligonucleotide-injected oocytes showed identical maturation time courses.

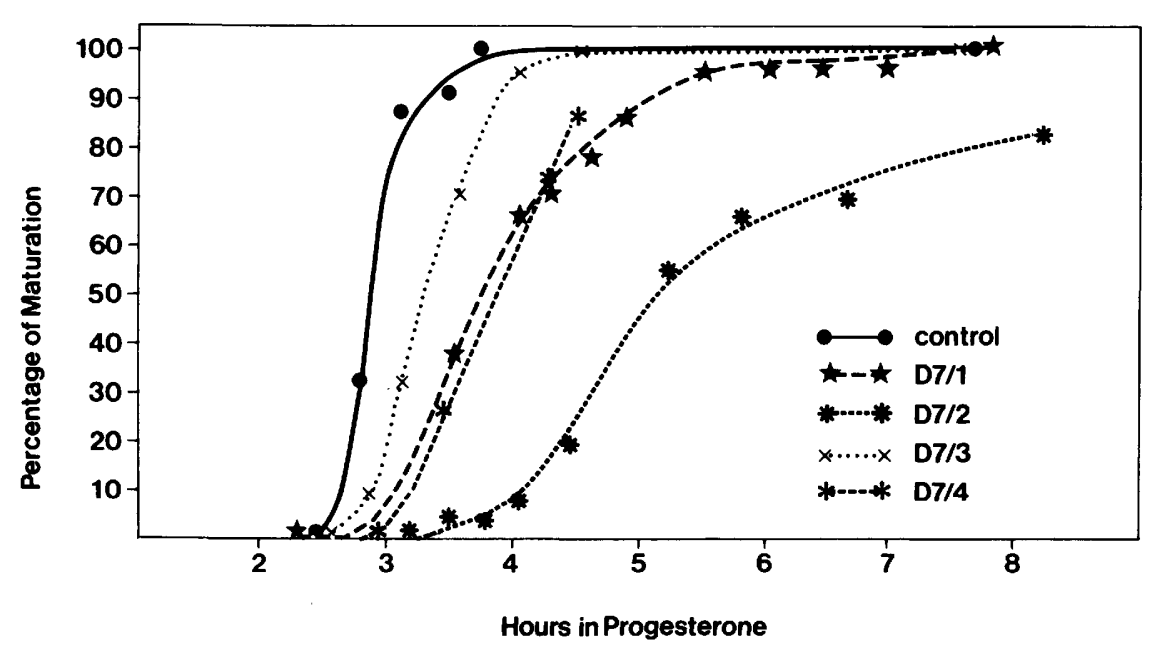




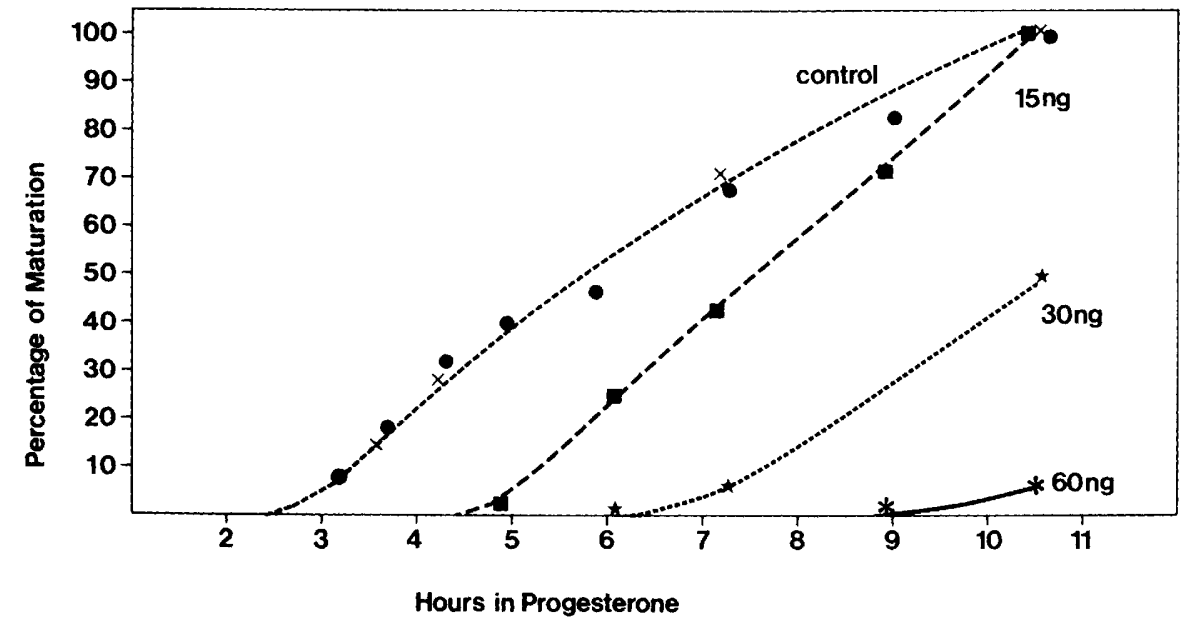

Figure 9. Dependence of maturation delay on oligonucleotide concentration. Stage VI oocytes were injected with 60 , 30 , or $15 \mathrm{ng}$ of oligonucleotide $\mathrm{D} 7 / 2$ per oocyte (as indicated), or with $60 \mathrm{ng}$ of the control oligonucleotide EBI896 per oocyte $(\mathrm{X})$, incubated for $>9 \mathrm{hr}$, and induced to mature by the addition of progesterone. The number of oocytes injected per oligonucleotide was $\geqslant 14$. The time courses of maturation were determined by scoring the formation of maturation spots under the dissecting microscope, as well as by fixation and sectioning of the oocytes at the end of the experiment. $(\bullet)$ Noninjected oocytes. turn, suggests a dependence on the amount of D7 protein allowed to accumulate in these oocytes.

\section{Discussion}

These experiments demonstrate that in $X$. laevis stage VI oocytes, an endogenous mRNA that is translationally repressed at this stage can be destroyed by injection of an antisense oligodeoxynucleotide. Oligonucleotide-mediated mRNA destruction in $X$. laevis had been shown previously for exogenous RNAs, as well as recently for endogenous RNAs (see introductory section). The efficiency of mRNA destruction in these studies varied for different transcripts and oligonucleotides. It is likely to depend on the accessibility of a given oligonucleotide to its complementary region on the RNA which, in turn, is determined by the secondary structure of the RNA and its association with protein. Especially in the case of an mRNA that is translationally repressed in oocytes /like D7 mRNA), it is likely that the RNA is tightly complexed with protein, limiting the regions available for hybridization to the oligonucleotide. In this context, it is actually surprising that all four oligonucleotides tested for their ability to mediate degradation of D7 mRNA were effective, although their exact efficiencies varied. We have also tested this approach with other $m R N A s$ that are translationally repressed in oocytes and have encountered oligonucleotides completely inefficient in this assay (E. Dworkin-Rastl, unpubl.). The extent of mRNA destruction depends very sensitively on the amount of oligonucleotide injected, with differences by factors of 2-4 having a strong effect (see also Dash et al. 1987; Jessus et al. 1988; Shuttleworth and Colman 1988). In our work, as well as in the studies cited above, oligonucleotide amounts in the range of 25-180 ng per oocyte were needed for successful mRNA destruction. At this concentration, the oligonucleotide is present at a molar excess of about $10^{5}$ over a moderately abundant RNA like D7 mRNA. The reason for the requirement for such high levels of oligonucleotide may be slow diffusion of the oligonucleotide, as well as a low rate of hybridization that would be expected in oocytes at am- bience. Furthermore, we and others /Cazenave et al. 1987a) have shown that oligonucleotides are very shortlived in Xenopus oocytes. The initial mRNA degradation products obtained with the different oligonucleotides are discrete and consistent with an RNase H-mediated cleavage mechanism (Dash et al. 1987; Shuttleworth and Colman 1988). RNase $H$ cleavage products are unstable in the oocyte and eventually become undetectable by Northern blot analysis. We have observed some variability in the efficiency of mRNA degradation by a given oligonucleotide with different batches of oocytes, which could be a reflection of variation in RNase $\mathrm{H}$ levels.

The possibility to generate oocytes specifically depleted of D7 mRNA provides a basis for studying the function of the $\mathrm{D} 7$ protein product. In untreated oocytes, D7 protein is first detectable during oocyte maturation. In experimental oocytes injected with an effective antiD7 mRNA oligonucleotide (e.g., D7/2) prior to progesterone treatment, the accumulation of D7 protein was reduced to background levels. These oocytes exhibited a significant increase in the time needed for oocyte maturation or, in several experiments, never achieved a high precentage of maturation during the time the experiment was followed (see Table 2). It is possible that the extent of delay in maturation is a reflection of the efficiency of D7 mRNA destruction. This hypothesis is consistent with the observed correlation between the efficiencies of different anti-D7 mRNA oligonucleotides in mediating mRNA degradation and the different extents of delay in maturation resulting from these oligonucleotides (an exception to this correlation was oligonucleotide D $7 / 3$, as described in Results). Further evidence in support of this hypothesis is the observed dependence of the maturation delay on the amount of a given oligonucleotide injected. Thus, our current hypothesis is that D7 protein is required at a certain point in the maturation process and that maturation cannot proceed beyond this point unless a threshold amount of D7 protein is provided. This threshold amount must be $\leqslant 20 \%$ of the 'wild-type' D7 protein level, the background level of D7 protein in Western blots (see Results). However, on the 
basis of the current data, it cannot be excluded that D7 has only a nonessential role in maturation and represents a protein whose presence, not strictly required, only speeds up maturation. The increased accumulation of D7 protein after fertilization might indicate an additional function of D7 during early development. A more detailed analysis of the D7 null phenocopy is in preparation.

\section{Materials and methods}

\section{RNA preparations and Northern analysis}

Embryos were staged according to Nieuwkoop and Faber (1967) and oocytes according to Dumont (1972). RNA was extracted from staged embryos, staged oocytes, or total ovary, and poly $(\mathrm{A})^{+}$RNA was prepared as described in Dworkin and Dawid (1980). For analysis of oligonucleotide-mediated RNA degradation, total RNA was prepared from samples of three oocytes each. Northern analysis with nick-translated plasmid probes was carried out as described previously (Dworkin et al. 1984), except that hybridization and wash conditions were according to Church and Gilbert (1984).

\section{Differential oligonucleotide hybridization}

Synthetic RNA transcripts were made with SP6 RNA polymerase (Boehringer-Mannheim) according to Melton et al. (1984), using as templates (1) a plasmid containing the $P_{s t I-}$ HindIII fragment of clone D7.0 (nucleotides 570-999, Fig. 3B) inserted in to the respective sites of the vector pGEM4 (Promega Biotec) and linearized with PvuII to yield an SP6 transcript of $\sim 600$ nucleotides, and (2) plasmid D7.1, linearized with ScaI to yield an SP6 transcript of $\sim 2900$ nucleotides. Differential hybridization conditions were determined using oligonucleotides EBI1016 and EBI1017 (specific for sequence D7.0 and D7.1, respectively; Table 1) end-labeled with $\mathrm{T} 4$ polynucleotide kinase to a specific activity of $\sim 5000 \mathrm{Ci} / \mathrm{mmole}$ and hybridized to Northern blot filters containing the synthetic RNAs $\left(10^{6} \mathrm{cpm} /\right.$ lane). Differential signals were obtained by hybridization overnight at $65^{\circ} \mathrm{C}$ in $0.5 \mathrm{M} \mathrm{NaHPO}_{4},(\mathrm{pH} 7.2), 1 \mathrm{~mm}$ EDTA, $1 \%$ bovine serum albumin (BSA), and 7\% SDS, followed by a washing protocol of $15 \mathrm{~min}$ at room temperature in $0.45 \mathrm{M}$ $\mathrm{NaCl}, 0.05 \mathrm{M} \mathrm{Na}$-citrate, $5 \% \mathrm{SDS}$, and $0.5 \% \mathrm{BSA}_{\text {; then }} 15 \mathrm{~min}$ at room temperature in $0.45 \mathrm{M} \mathrm{NaCl}, 0.05 \mathrm{M} \mathrm{Na}$-citrate, and $1 \%$ SDS; and finally for $10 \mathrm{~min}$ at $65^{\circ} \mathrm{C}$ in $0.45 \mathrm{M} \mathrm{NaCl}, 0.05 \mathrm{M}$ Na-citrate, and $1 \%$ SDS.

\section{Oligonucleotide synthesis, purification, and stability in oocytes}

Oligodeoxynucleotides were synthesized with an Applied Biosystems DNA synthesizer, purified by reverse-phase high performance liquid chromatography (HPLC), following the protocol of Applied Biosystems, and dissolved in water. The radiolabeled oligonucleotide was prepared by end labeling trace amounts of $\mathrm{D} 7 / 1$ oligonucleotide (Table 1) with $\mathrm{T} 4$ polynucleotide kinase, followed by extensive dialysis at $4^{\circ} \mathrm{C}$ against water (dialysis tubing: molecular weight cutoff of 3500) and lyophilization. The stability of oligodeoxynucleotides in stage VI oocytes was determined by injecting $60 \mathrm{ng}(26,000 \mathrm{cpm})$ of $\mathrm{D} 7 / 1$ oligonucleotide per oocyte, incubating oocytes for various times, and quick-freezing oocytes at $-70^{\circ} \mathrm{C}$. Lysates from individual oocytes were prepared by crushing each oocyte in $12 \mu \mathrm{l}$ sequencing gel sample buffer (Maxam and Gilbert 1980), boiling for $2 \mathrm{~min}$, and centrifuging in the microfuge for $3 \mathrm{~min}$. An ali- quot of the supernatant containing $5000 \mathrm{cpm}$ was analyzed by separation on a $20 \%$ DNA sequencing gel and subsequent autoradiography.

\section{Screening of an egg cDNA library, DNA sequencing, and computer programs}

An egg cDNA plasmid library, prepared from poly $(A)^{+}$RNA isolated from unfertilized eggs by GC tailing into the vector pGEM4 (Promega Biotec), was screened for D7 sequences using a nick-translated insert fragment of clone D7.0 (NcoI-EcoRI fragment, nucleotides 230-458, Fig. 3B). DNA sequences were determined on both strands by either the method of Maxam and Gilbert (1980) or by chain-termination sequencing of doublestranded DNA templates (Chen and Seeburg 1985), using a Sequenase sequencing kit (USB) and oligodeoxynucleotide primers. Homology searches were performed of the Protein Identification Resource data bank (release 10.0), using the FASTP program (Lipman and Pearson 1985). Calculations of pI value and hydrophobicity utilized the IBI DNA/protein sequence analysis software package.

\section{Expression vector construction and fusion protein isolation}

The BstEII-HindIII fragment of clone D7.0 (nucleotides 225-999, Fig. 3B), made blunt ended at the BstEII site by fill in with reverse transcriptase, was cloned between the $B a m H I$ site (filled in with reverse transcriptase) and the HindIII site of the $\beta$-galactosidase fusion protein vector pUR292 (Rüther and Müller-Hill 1983). This resulted in an in-frame fusion of the D7 fragment to the carboxy-terminal end of $\beta$-galactosidase. The resulting plasmid was used to transform $E$. coli $\mathrm{K}-12$ strain 71-18 (Messing et al. 1977). Fusion protein was induced by the addition of isopropyl- $\beta$-thiogalactoside (Pharmacia) to a final concentration of $1.5 \mathrm{mM}$ to $\log$-phase bacteria $\left(O D_{590}=1.0\right)$ and grown for an additional $2 \mathrm{hr}$ at $37^{\circ} \mathrm{C}$. Fusion protein was purified from the supernatant fraction of the bacterial lysate by affinity chromatography on a $p$-aminophenyl- $\beta$ - $D$-thiogalactopyranoside-agarose column (Sigma) according to Ullmann (1984). Rabbits were immunized, and the resulting antiserum was affinity-purified in two steps to obtain antibodies directed against D7: (1) by eliminating antibodies binding to $\beta$-galactosidase, and (2) by selecting for antibodies binding to the fusion protein. Details of the procedures used for fusion protein isolation are described elsewhere (Smith et al. 1988). Serum from two rabbits immunized with the fusion protein gave indistinguishable results on Western blots.

\section{Protein extracts and Western blots}

Eggs and embryos were dejellied in $2 \%$ cysteine- $\mathrm{HCl}(\mathrm{pH} 8)$. Larger-scale extracts of oocytes, eggs, embryos, and adult tissues were made as described previously (Segil et al. 1988). For the analysis of oligonucleotide-injected oocytes, protein was prepared from samples of two to three oocytes by homogenizing the cells on ice in $25 \mu \mathrm{l}$ full-strength modified amphibian Ringer's solution (Vincent et al. 1986). The homogenate was centrifuged for $30 \mathrm{sec}$ at $4^{\circ} \mathrm{C}$ in a microfuge; and the supernatant analyzed by Western blotting. Western blots were done as described previously (Segil et al. 1988), using $7 \mu \mathrm{g} / \mathrm{ml}$ affinity column-purified anti-D7 antibodies and, where indicated, antiserum against $X$. laevis enolase (Segil et al. 1988) at a dilution of $1: 5000$.

Oocyte injections, in vitro maturation, and histology

Oocytes were freed manually from the ovary in full-strength 
modified amphibian Ringer's solution (Vincent et al. 1986), and stage VI oocytes were selected for injection. Up to $80 \mathrm{nl}$ of oligonucleotide solution per oocyte was injected; the amounts of oligonucleotide injected are given in Results. Oocyte maturation was induced by the addition of $1-2 \mu \mathrm{g} / \mathrm{ml}$ progesterone in Ringer's (above) containing (in some experiments) $1 \%$ calf serum or fetal calf serum. For histological evaluation of maturation, the oocytes were fixed overnight in $100 \%$ cold $\left(4^{\circ} \mathrm{C}\right)$ methanol, embedded in paraplast, and sectioned; sections were stained with Giemsa solution (Merck). Alternatively, oocytes were fixed in $5 \%$ trichloroacetic acid for $5 \mathrm{~min}$, bisected with a blade, and maturation evaluated under the dissecting microscope.

\section{Acknowledgments}

We wish to acknowledge Hermann Mahr for synthesis of oligodeoxyribonucleotides, and Brenda Demeties, Anthony Shrutkowski, and Heide Wocelka for excellent technical assistance. We thank John Gerhart, Jeff Roberts, and Tim Hunt for stimulating discussions during the course of this work. Some of these studies were supported by National Institutes of Health grant GM-37981 to M.B.D. and a Muscular Dystrophy Association postdoctoral fellowhip to R.C.S.

\section{Note}

Sequence data described in this paper have been submitted to the EMBL/GenBank Data Libraries.

\section{References}

Bairoch, A. and J.-M. Claverie. 1988. Sequence patterns in protein kinases. Nature 331: 22.

Bass, B.L. and H. Weintraub. 1987. A developmentally regulated activity that unwinds RNA duplexes. Cell 48: 607-613.

Brenner, S. 1987. Phosphotransferase sequence homology. Nature 329: 21 .

Cazenave, C., M. Chevrier, N.T. Thuong, and C. Hélène. 1987a. Rate of degradation of $[\alpha]$-and $[\beta]$-oligodeoxynucleotides in Xenopus oocytes. Implications for anti-messenger strategies. Nucleic Acids Res. 15: 10507-10521.

Cazenave, C., N. Loreau, J.-J. Toulmé, and C. Hélène. 1986. Anti-messenger oligonucleotides: specific inhibition of rabbit $\beta$-globin synthesis in wheat germ extracts and Xenopus oocytes. Biochimie 68: 1063-1069.

Cazenave, C., N. Loreau, N.T. Thuong, J.-J. Touliné, and C. Héléne. 1987b. Enzymatic amplification of translation inhibition of rabbit $\beta$-globin mRNA mediated by anti-messenger oligodeoxynucleotides convalently linked to intercalating agents. Nucleic Acids Res. 15: 4717-4736.

Chen, E.Y. and P.H. Seeburg. 1985. Supercoil sequencing: a fast and simple method for sequencing plasmid DNA. DNA 4: $165-170$.

Church, G.M. and W. Gilbert. 1984. Genomic sequencing. Proc. Natl. Acad. Sci. 81: 1991-1995.

Dash, P., I. Lotan, M. Knapp, E.R. Kandel, and P. Goelet. 1987. Selective elimination of mRNAs in vivo: complementary oligodeoxynucleotides promote RNA degradation by an RNase H-like activity. Proc. Natl. Acad. Sci. 84: 78967900.

Doolittle, R.F. 1986. Of URFs and ORFs. University Science Books, Mill Valley, California.

Dumont, J.N. 1972. Oogenesis in Xenopus laevis (Daudin) 1. Stages of oocyte development in laboratory maintained animals. J. Morphol. 136: 153-180.
Dworkin, M.B. and I.B. Dawid. 1980. Construction of a cloned library of expressed embryonic gene sequences from Xenopus laevis. Dev. Biol. 76: 435-448.

Dworkin, M.B. and E. Dworkin-Rastl. 1985. Changes in RNA titers and polyadenylation during oogenesis and oocyte maturation in Xenopus laevis. Dev. Biol. 112: 451-457.

Dworkin, M.B., A. Shrutkowski, and E. Dworkin-Rastl. 1985. Mobilization of specific maternal RNA species into polysomes after fertilization in Xenopus laevis. Proc. Natl. Acad. Sci. 82: 7636-7640.

Dworkin, M.B., A. Shrutkowski, M. Baumgarten, and E. Dworkin-Rastl. 1984. The accumulation of prominent tadpole mRNAs occurs at the beginning of neurulation in Xenopus laevis embryos. Dev. Biol.. 106: 289-295.

Edelman, A.M., D.K. Blumenthal, and E.G. Krebs. 1987. Protein serine/threonine kinases. Annu. Rev. Biochem. 56: 567613.

Harland, R. and H. Weintraub. 1985. Translation of mRNA injected into Xenopus oocytes is specifically inhibited by antisense RNA. J. Cell Biol. 101: 1094-1099.

Holwill, S., J. Heasman, C.R. Crawley, and C.C. Wylie. 1987. Axis and germ line deficiencies caused by U.V. irradiation of Xenopus oocytes cultured in vitro. Development 100: 735743.

Jessus, C., C. Cazenave, R. Ozon, and C. Hélène. 1988. Specific inhibition of endogenous $\beta$-tubulin synthesis in Xenopus oocytes by anti-messenger oligodeoxynucleotides. Nucleic Acids Res. 16: 2225-2233.

Kawasaki, E.S. 1985. Quantitative hybridization-arrest of mRNA in Xenopus oocytes using single-stranded complementary DNA or oligonucleotide probes. Nucleic Acids Res. 13: 4991-5004.

Kozak, M. 1987. An analysis of 5 '-noncoding sequences from 699 vertebrate messenger RNAs. Nucleic Acids Res. 15: $8125-8148$.

Lipman, D.J. and W.R. Pearson. 1985. Rapid and sensitive protein similarity searches. Science 227: 1435-1441.

Maxam, A.M. and W. Gilbert. 1980. Sequencing end-labeled DNA with base-specific chemical cleavages. Methods Enzymol. 65: 499-560.

Melton, D.A. 1985. Injected anti-sense RNAs specifically block messenger RNA translation in vivo. Proc. Natl. Acad. Sci. 82: $144-148$.

Melton, D.A., P.A. Krieg, M.R. Rebagliati, T. Maniatis, K. Zinn, and M.R. Green. 1984. Efficient in vitro synthesis of biologically active RNA and RNA hybridization probes from plasmids containing a bacteriophage SP6 promoter. Nucleic Acids Res. 12: 7035-7056.

Messing, J., B. Gronenborn, B. Müller-Hill, and P.H. Hofschneider. 1977. Filamentous coliphage M13 as a cloning vehicle: insertion of a HindII fragment of the lac regulatory region in M13 replicative form in vitro. Proc. Natl. Acad. Sci. 74: 3642-3646.

Nieuwkoop, P.D. and J. Faber. 1967. Normal table of Xenopus laevis (Daudin), 2nd ed. North-Holland, Amsterdam.

Rebagliati, M.R. and D.A. Melton. 1987. Antisense RNA injections in fertilized frog eggs reveal an RNA duplex unwinding activity. Cell 48: 599-605.

Rogers, S., R. Wells, and M. Rechsteiner. 1986. Amino acid sequences common to rapidly degraded proteins: the PEST hypothesis. Science 234: 364-368.

Rüther, U. and B. Müller-Hill. 1983. Easy identification of cDNA clones. EMBO I. 2: 1791-1794.

Segil, N., A. Shrutkowski, M.B. Dworkin, and E. DworkinRastl. 1988. Enolase isozymes in adult and developing Xenopus laevis and characterization of a cloned enolase se- 


\section{Smith et al.}

quence. Biochem. J. 251: 31-39.

Shaw, G. and R. Kamen. 1986. A conserved AU sequence from the $3^{\prime}$ untranslated region of GM-CSF mRNA mediates selective mRNA degradation. Cell 46: 659-667.

Shuttleworth, J. and A. Colman. 1988. Antisense oligonucleotide-directed cleavage of mRNA in Xenopus oocytes and eggs. EMBO J. 7: 427-434.

Smith, R.C., E. Dworkin-Rastl, and M.B. Dworkin. 1988. Expression of a histone $\mathrm{Hl}$-like protein is restricted to early Xenopus development. Genes Dev. 2: 1284-1295.

Ullmann, A. 1984. One-step purification of hybrid proteins which have $\beta$-galactosidase activity. Gene 29: 27-31.

Vincent, J.-P., G.F. Oster, and J.C. Gerhart. 1986. Kinematics of gray crescent formation in Xenopus eggs: the displacement of subcortical cytoplasm relative to the egg surface. Dev. Biol. 113: 484-500.

Wormington, W.M. 1986. Stable repression of ribosomal protein L1 synthesis in Xenopus oocytes by microinjection of antisense RNA. Proc. Natl. Acad. Sci. 83: 8639-8643. 


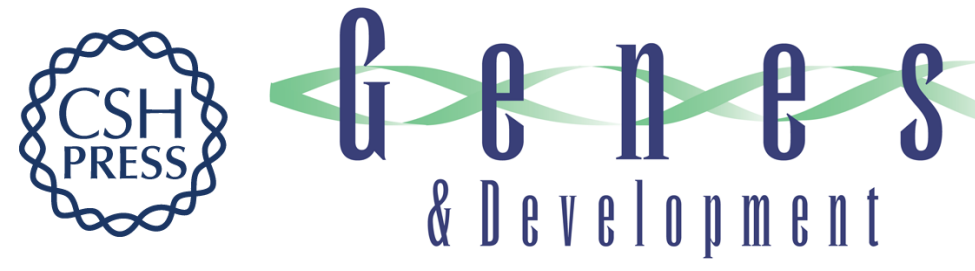

\section{Destruction of a translationally controlled mRNA in Xenopus oocytes delays progesterone-induced maturation.}

R C Smith, M B Dworkin and E Dworkin-Rastl

Genes Dev. 1988, 2:

Access the most recent version at doi:10.1101/gad.2.10.1296

References This article cites 35 articles, 12 of which can be accessed free at:

http://genesdev.cshlp.org/content/2/10/1296.full.html\#ref-list-1

License

Email Alerting

Service

Receive free email alerts when new articles cite this article - sign up in the box at the top right corner of the article or click here.

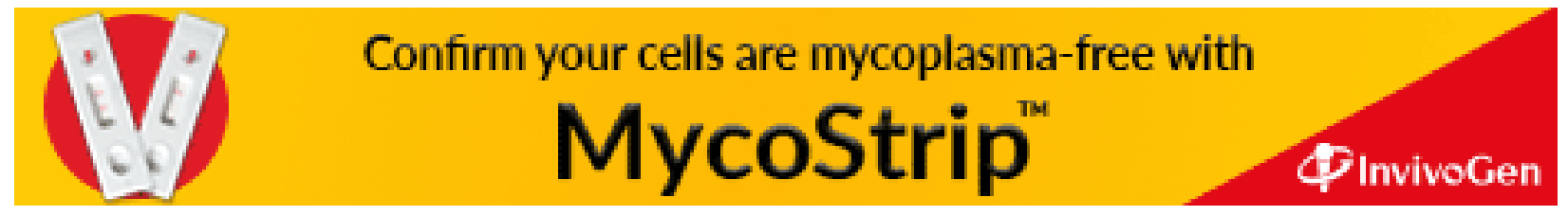

